Departement für Pferde, Abteilung für Anästhesiologie der Vetsuisse-Fakultät Universität Zürich

Direktor: Prof. Dr. med. vet. Anton Fürst

\title{
Evaluation of different dose rate combinations of ketamine, romifidine and azaperone for castration of 3-4 and 5-6 weeks old piglets
}

\author{
Inaugural-Dissertation \\ zur Erlangung der Doktorwürde der \\ Vetsuisse-Fakultät Universität Zürich
}

vorgelegt von

Veronika Cap

Tierärztin

von Luzern LU

\begin{abstract}
genehmigt auf Antrag von
Prof. Dr. med. vet. PhD Regula Bettschart-Wolfensberger, Referentin Prof. Dr. med. vet. PhD Fredi Janett, Korreferent
\end{abstract}




\section{Index}

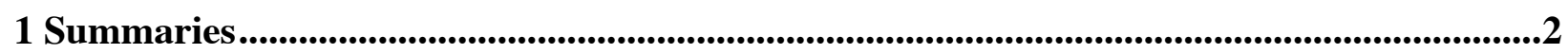

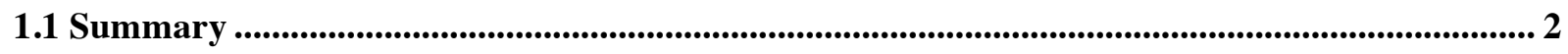

1.2 Zusammenfassung .................................................................................................................................... 3

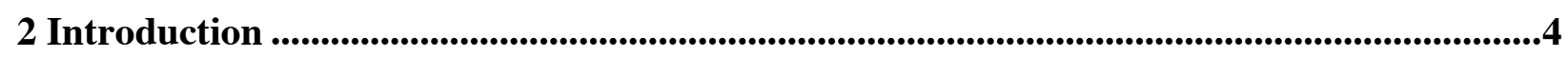

3 Animals, material and methods .............................................................................................6

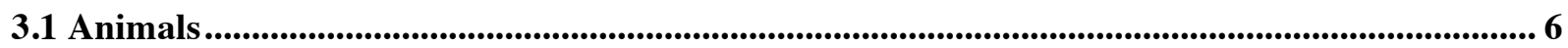

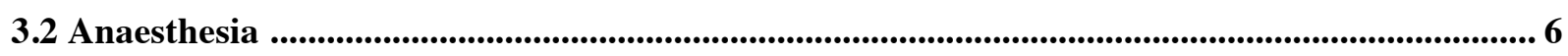

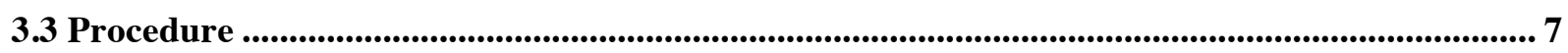

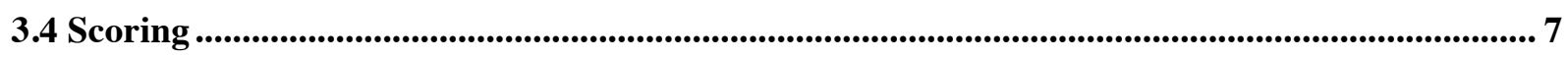

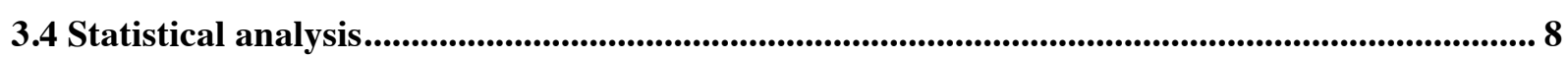

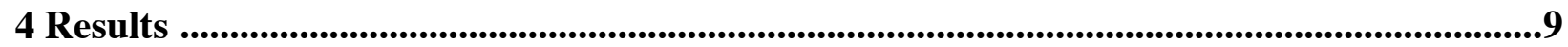

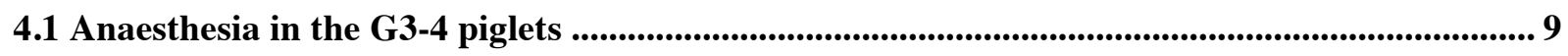

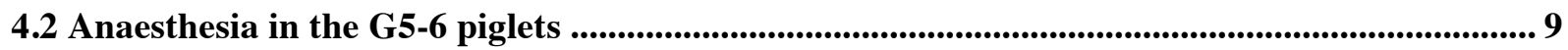

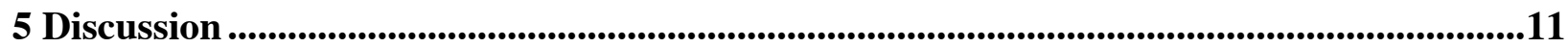

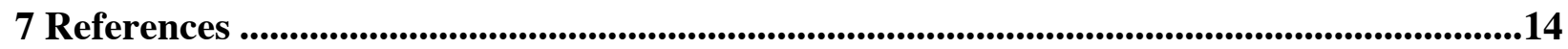

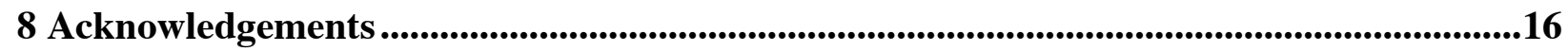

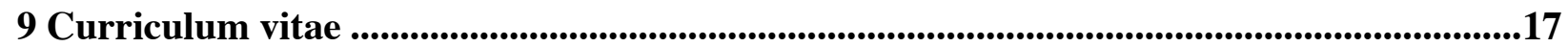




\section{Summaries}

\subsection{Summary}

Aim of this study was to establish an intramuscularly (IM) injectable anaesthesia protocol for castration of 3-4 (G3-4) and 5-6 weeks (G5-6) old piglets.

Dose rate combinations of ketamine, azaperone and romifidine were tested according to a dose rate decision tree (DRT). We wanted to identify doses that provide calm anaesthesia induction, reaction-free anaesthesia for castration and smooth recovery within 2 hours. When a combination failed to meet those criteria in 2 piglets, the next dosage of the DRT was tested. In G3-4 4 combinations were tested in 14 piglets with dose rates of $10-20 \mathrm{mg} / \mathrm{kg}$ ketamine, 3 $\mathrm{mg} / \mathrm{kg}$ azaperone and $0.15-0.20 \mathrm{mg} / \mathrm{kg}$ romifidine IM. Induction was smooth in all piglets, but depth of anaesthesia or recovery (11 and 6 piglets) were insufficient. In G5-6 5 combinations were tested in 37 piglets with dose rates of $10-20 \mathrm{mg} / \mathrm{kg}$ ketamine, $3-4 \mathrm{mg} / \mathrm{kg}$ azaperone and $0.15-0.20 \mathrm{mg} / \mathrm{kg}$ romifidine IM. Induction was smooth in all piglets but 2. Depth of anaesthesia or recovery (17 and 7 piglets) were insufficient.

In the present study with 3-4 and 5-6 weeks old piglets, acceptable quality of anaesthesia could not be achieved despite using very high drug dose rates.

Key words: piglet, injectable anaesthesia, castration, romifidine, ketamine 


\subsection{Zusammenfassung}

Ziel dieser Studie war die Etablierung eines Protokolls zur intramuskulären (IM) Anästhesie für die Kastration von 3-4 (G3-4) und 5-6 Wochen (G5-6) alten Ferkeln.

Dosis-Kombinationen mit Ketamin, Azaperon und Romifidin wurden anhand eines DosisEntscheidungsbaumes (DEB) getestet. Wir wollten diejenige Dosis bestimmen, welche eine ruhige Anästhesieeinleitung, eine reaktionsfreie Anästhesie zur Kastration und eine ruhige, innerhalb von 2 Stunden abgeschlossene Aufwachphase gewährleistet. Wenn eine Kombination diese Kriterien bei 2 Ferkeln nicht erfüllte, wurde die nächste Dosis des DEB geprüft.

In G3-4 wurden 4 Kombinationen mit Dosierungen von 10-20 mg/kg Ketamin, 3 mg/kg Azaperon und 0.15-0.20 mg/kg Romifidin IM an 14 Ferkeln getestet. Die Anästhesieeinleitung war ruhig bei allen Ferkeln, jedoch waren Anästhesietiefe oder Aufwachphase (11 beziehungsweise 6 Ferkel) ungenügend. In G5-6 wurden 5 Kombinationen mit Dosierungen von 3-4 mg/kg Azaperon, 10-20 mg/kg Ketamin und 0.15-0.20 mg/kg Romifidin IM an 37 Ferkeln getestet. Die Anästhesieeinleitung war mit Ausnahme von 2 Ferkeln ruhig. Die Anästhesietiefe oder die Aufwachphase (17 beziehungsweise 7 Ferkel) waren ungenügend.

In der vorliegenden Studie wurde trotz der Anwendung von hohen Dosierungen bei 3-4 und 5-6 Wochen alten Ferkeln keine akzeptable Anästhesiequalität erreicht.

Schlüsselwörter: Ferkel, Injektionsanästhesie, Kastration, Romifidin, Ketamin 


\section{Introduction}

Meat of boars can exhibit an unpleasant odour that is rejected by consumers (Huber-Eicher and Spring, 2008). The current common practice to avoid boar taint in Switzerland is the surgical castration of male piglets.

According to the Swiss animal welfare legislation the provision of analgesia during surgical castration is mandatory (TSchG Art. 44). In order to accomplish this, piglets are either administered preoperatively a non-steroidal inflammatory agent and castrated under inhalational anaesthesia with isoflurane or anaesthesia is obtained by the intramuscular injection of anaesthetics.

For smaller farms, inhalation anaesthesia is not an option as acquisition and servicing of inhalation anaesthesia equipment is too expensive. Progressive use of inhalation anaesthesia machines in larger farms has led to concerns regarding accumulation and transmission of infectious agents. Moreover, isoflurane represents a health risk for exposed farmers. In a recent survey $11 \%$ of farmers working with inhalation anaesthesia complained about headaches (Enz et al., 2013a). In addition, there is evidence that isoflurane promotes Alzheimer's disease formation (Jiang and Jiang, 2015). Therefore, it is likely that the need for alternatives such as injectable anaesthesia will rise.

The achievement of a satisfying anaesthesia by intramuscular injection of anaesthetics is a challenging task in pigs (Bettschart-Wolfensberger et al., 2013; Berchtold, 2015). To the knowledge of the authors, there is no reliable one-shot intramuscular injection protocol for castration of pigs that provides deep and safe anaesthesia with smooth recoveries. As ketamine is the only anaesthetic that is registered for pigs in Switzerland, all combinations used in piglet anaesthesia include this drug.

Ketamine produces dose-dependent hypnosis and mainly somatic analgesia (Ammer and Potschka, 2010). When applied alone, ketamine provokes muscle tremor and extensor rigidity (Lin, 2014). To minimize these side effects, azaperone or $\alpha 2$-agonists need to be coadministered. Despite their additive properties, resulting analgesia for surgical manipulations is often insufficient (Lin, 2014). With the commonly used protocol $(15 \mathrm{mg} / \mathrm{kg}$ ketamine, $5 \mathrm{mg} / \mathrm{kg}$ azaperone, $0.2 \mathrm{mg} / \mathrm{kg}$ butorphanol IM) a satisfying anaesthesia for castration was attained in $86 \%$ of 3 weeks old piglets (Nussbaumer et al., 2011). A large-scale observational study even reported movement during surgery in $34 \%$ of piglets $(n=371)$ undergoing castration at the age of 1-4 weeks. Moreover, recovery was prolonged (> $112 \pm$ $22.7 \mathrm{~min}$ ) in $50 \%$ and excitations during recovery occurred in $17 \%$ of piglets (Enz et al., 
2013b). In order to improve quality of anaesthesia, $\alpha 2$-agonists are added to improve hypnosis, analgesia and muscle relaxation (Lin, 2014). However, implementation of the $\alpha_{2}-$ agonist detomidine $(0.08 \mathrm{mg} / \mathrm{kg})$ to a protocol with $10 \mathrm{mg} / \mathrm{kg}$ ketamine, $4 \mathrm{mg} / \mathrm{kg}$ azaperone and $0.2 \mathrm{mg} / \mathrm{kg}$ butorphanol IM was not successful: 4 of 12 animals showed inadequate anaesthesia (Heinonen et al., 2009). When xylazine, another less specific $\alpha 2$-agonist, was used in piglets, excitations during recovery occurred (Ganter et al., 1990). On the other hand, the use of romifidine, a newer $\alpha 2$-agonist, showed a calming effect on pigs, when dose rates lower than $0.2 \mathrm{mg} / \mathrm{kg}$ were used (Baab, 1986). A more recent study included therefore romifidine in the standard anaesthesia protocol (ketamine, azaperone, butorphanol) for castration of 1-2 weeks old piglets. Dose rates of 0.15 or $0.2 \mathrm{mg} / \mathrm{kg}$ romifidine IM resulted in satisfying depth of anaesthesia, however recoveries were accompanied by severe, unacceptable excitations (Berchtold, 2015).

In older piglets, several authors described more sufficient anaesthesia when compared to younger animals (Löscher, 1990; Enz et al., 2013b) as well as lower anaesthetic requirements (Kanngiesser, 1988; Lahrmann, 2006). However, in 9 weeks old swiss piglets standard anaesthesia $(15 \mathrm{mg} / \mathrm{kg}$ ketamine in combination with $5 \mathrm{mg} / \mathrm{kg}$ azaperone and $0.2 \mathrm{mg} / \mathrm{kg}$ butorphanol IM) showed an overall unsatisfactory quality for castration (BettschartWolfensberger et al., 2013). Therefore, we decided to test the use of ketamine-azaperone in combination with romfidine.

The aim of this study was to determine dose rates of ketamine, azaperone and romifidine that result in an anaesthesia protocol, which provides smooth anaesthesia induction, reaction-free anaesthesia for castration as well as smooth recovery complete within 2 hours in 3-4 weeks and 5-6 weeks old piglets. 


\section{Animals, material and methods}

\subsection{Animals}

This clinical study was performed in a prospective design and was in accordance with the guidelines for good clinical practice under the bylaws of the Swiss experimental animal research (ZH075/16). Piglets of 2 age groups were investigated separately: 3-4 weeks old suckling piglets (G3-4) and 5-6 weeks old weaned piglets (G5-6). Piglets of different breeds (Landrace, F1 (Landrace x Large White) and F1 x Duroc) were randomly chosen. They were housed on a commercial farm in Switzerland.

\subsection{Anaesthesia}

Dosage-combinations of ketamine (Ketanarkon 100® ad us. vet., Streuli Pharma AG, Uznach, Switzerland), azaperone (Stresnil ${ }^{\circledR}$ ad us. vet., Biokema, Lausanne, Switzerland) and romifidine (Sedivet ${ }^{\circledR}$ ad us. vet., Boehringer Ingelheim, Basel, Switzerland) were administered IM. To determine the optimal dose of each tested drug, a previously established decision tree was followed (Berchtold, 2015).

The starting doses tested were $10 \mathrm{mg} / \mathrm{kg}$ ketamine $+3 \mathrm{mg} / \mathrm{kg}$ azaperone $+0.15 \mathrm{mg} / \mathrm{kg}$ romifidine. Five min post-injection, depth of anaesthesia was assessed for the first time by means of reaction on touch and on pinching the nasal septum with 2 fingers. If no reaction was noted, castration was initiated. Otherwise, this procedure was repeated every 2 min until $10 \mathrm{~min}$ post-injection. If piglets still reacted by then, additional ketamine $(5 \mathrm{mg} / \mathrm{kg})$ and azaperone $(1 \mathrm{mg} / \mathrm{kg})$ were injected IM (=redosing) and $5 \mathrm{~min}$ waited until castration was initiated. In case of insufficient anaesthesia during castration, $0.1 \mathrm{ml} / \mathrm{kg}$ lidocaine (Lidocain $2 \%$ Streuli ${ }^{\circledR}$ ad us. vet., Streuli Pharma AG, Uznach, Switzerland) was injected into each testis and castration was performed another 2 min later.

A protocol was rejected when anaesthesia had to be deepened with ketamine-azaperone, lidocaine had to be given or anaesthesia was scored insufficient (score during castration $>8$, Table 1) and in case of excitement during anaesthesia induction/recovery or recovery longer than $2 \mathrm{~h}$ in 2 piglets. Thereafter, the protocol was modified according to the decision tree. This procedure was repeated until the dosages, that according to the literature had previously been determined as maximally applicable safe dose rates (ketamine: $20 \mathrm{mg} / \mathrm{kg}$, azaperone: 5 $\mathrm{mg} / \mathrm{kg}$, romifidine $0.2 \mathrm{mg} / \mathrm{kg}$ ), were reached. Body weights for dosage calculations were estimated (estimated bodyweight $\mathrm{eBW}$ ). After castration, the real body weight (rBW) was determined for retrospective calculation of the effective dose rate given and the percentage of over- respectively underestimation. 
Immediately after castration, piglets received $0.4 \mathrm{mg} / \mathrm{kg}$ meloxicam (Metacam 20® ad us. vet., Boehringer Ingelheim, Basel, Switzerland) IM.

\subsection{Procedure}

The procedure was subdivided into induction of anaesthesia, castration and recovery phase. For induction of anaesthesia, piglets were placed in groups of 2-3 animals (depending on litter size) in a box. After estimation of body weight, the mixed anaesthetics were applied into the neck musculature.

After scrubbing, incision of the skin and exteriorization of the testicles, a Hausmann emasculator (Provet AG, Lyssach, Switzerland) was used for their removal. In G5-6, the funicular cords were ligated (Vicryl 1, Johnson \& Johnson Medical, Spreitenbach, Switzerland) before the use of the emasculator.

For recovery, all piglets were placed together in boxes provided with heating lamps.

\subsection{Scoring}

Castration was scored whilst being performed, induction and recovery phase were videotaped and scored retrospectively by 2 observers. Previously described scoring criteria were used and modified according to suggestions from the author (Berchtold, 2015) (Table 1, 2).

During induction of anaesthesia, the intensity of paddling was scored (0-3) and excitement recorded (yes/no). It was noted, whether induction of anaesthesia was successful within 10 min after injection (yes/no). Anaesthetic depth was scored at each step of castration: positioning of the pig, skin incision, exteriorization of testicles and pinching the spermatic cord (first and second). Quantity (0-3) and extent (0-4) of movements and number of vocalizations (0-3) were scored and a total castration score (0-50) was calculated. During recovery, the intensity of paddling was scored (0-3) and excitement recorded (yes/no). In addition to this, all phases were assessed on a visual analog scale (VAS) with 0 meaning ideal, best imaginable and 10.0 meaning worst case for each phase.

All phases were timed and time until recovery was complete (ability to walk 4 steps in a row) was determined.

Rejection criteria for any of the protocols included excitement during induction of anaesthesia, insufficient anaesthetic depth (defined as redosing of ketamine-azaperone $10 \mathrm{~min}$ after anaesthesia induction necessary, lidocaine needed during castration or castration score $>$ 8 ) and poor (excitement, cramps, muscular spasms) or prolonged ( $>2$ hours of duration) recovery. 
In cases where redosing of ketamine-azaperone was necessary, castration and recovery of anaesthesia were not assessed anymore. In case of lidocaine administration, castration was not assessed.

Table 1: Scoring of anaesthetic depth during castration. A positioning, B skin incision, C exteriorization, D1 pinching spermatic cord 1, D2 pinching spermatic cord 2.

\begin{tabular}{|l|l|l|l|l|l|l|l|l|l|l|l|l|l|l|l|l|l|l|}
\hline Score & \multicolumn{5}{|c|}{ Movement: quantity } & \multicolumn{5}{|c|}{ Movement: extent } & \multicolumn{3}{|c|}{ Vocalization: number } \\
\hline & A & B & C & D1 & D2 & & A & B & C & D1 & D2 & & A & B & C & D1 & D2 & \\
\hline $\mathbf{0}$ & & & & & & None & & & & & & None & & & & & None \\
\hline $\mathbf{1}$ & & & & & $1 \mathrm{x}$ & & & & & & $\begin{array}{l}1 \\
\text { leg/head }\end{array}$ & & & & & $1 \mathrm{x}$ \\
\hline $\mathbf{2}$ & & & & & & $\begin{array}{l}\text { Seve- } \\
\text { ral x }\end{array}$ & & & & & & $\begin{array}{l}\text { Several } \\
\text { legs/ } \\
\text { incl. head }\end{array}$ & & & & & & $\begin{array}{l}\text { Seve } \\
\text { ral x }\end{array}$ \\
\hline $\mathbf{3}$ & & & & & $\begin{array}{l}\text { Conti- } \\
\text { nuous }\end{array}$ & & & & & & $\begin{array}{l}\text { Incl. } \\
\text { spine }\end{array}$ & & & & & & $\begin{array}{l}\text { Conti- } \\
\text { nuous }\end{array}$ \\
\hline $\mathbf{4}$ & & & & & & & & & $\begin{array}{l}\text { Worse } \\
\text { than 3 }\end{array}$ & & & & & \\
\hline
\end{tabular}

Table 2: Scoring of paddling during induction of anaesthesia and recovery.

\begin{tabular}{|l|l|}
\hline Score & Paddling \\
\hline $\mathbf{0}$ & None \\
\hline $\mathbf{1}$ & $1 \mathrm{x}$ and mild \\
\hline $\mathbf{2}$ & $1 \mathrm{x}$ and severe or several $\mathrm{x}$ \\
\hline $\mathbf{3}$ & Continuous \\
\hline
\end{tabular}

\subsection{Statistical analysis}

Statistical analysis was performed by means of descriptive statistics and normality was tested by means of the Shapiro-Wilk test. For these purposes, Microsoft Excel 2016 was used. Normally distributed data are presented as mean \pm standard deviation (SD), not normally distributed data as median \pm standard error $(\mathrm{SE})$. 


\section{Results}

\subsection{Anaesthesia in the G3-4 piglets}

In G3-4 14 piglets aged $22 \pm 1$ days and weighing $6.1 \pm 1.6 \mathrm{~kg}$ were investigated. Breeds included were F1 (Landrace $x$ Large White, $n=6)$ and F1 x Duroc $(n=8)$. The administered dosages deviated by $+8 \pm 8 \%$ from the dosage calculated for $\mathrm{rBW}$, so all the piglets received higher dose rates than presumed.

A total of 4 anaesthetic protocols were tested, details are given in Table 3.

Induction of anaesthesia was smooth in all piglets and took $6.3 \pm 1.4 \mathrm{~min}$. Two piglets did not achieve sufficient depth of anaesthesia within 10 min after injection and required redosing with ketamine-azaperone, another 4 piglets were administered lidocaine intratesticularly and in 5 piglets anaesthetic depth was nonsatisfying (VAS $7.8 \pm 1.4$, total score of $16.4 \pm 3.1 \mathrm{vs}$. VAS $0.7 \pm 0.8$ and score of $1.7 \pm 2.9$ in animals with sufficient anaesthesia). Overall, anaesthetic plane was insufficient in 11 of 14 piglets.

Recovery was unsatisfying in 4 piglets with strong ataxia, excitement and severe paddling (score of 2). Of these animals, 3 had received $20 \mathrm{mg} / \mathrm{kg}$ ketamine. Additionally, in 2 piglets recovery took $>2$ hours.

The end of the decision tree was reached without finding a satisfying protocol in this age group.

Table 3: Ketamine (ket), azaperone (aza) and romfidine (rom) dosages tested and reasons for rejection of the tested anaesthesia protocols in 3-4 weeks old piglets.

\begin{tabular}{|l|l|l|c|c|c|c|c|c|c|}
\hline \multicolumn{3}{|c|}{ Dosage (mg/kg) } & Piglets & \multicolumn{6}{|c|}{ Reasons for rejection of the tested protocol } \\
\hline Ket & Aza & Rom & Total & Induction & \multicolumn{3}{|c|}{ Anaesthetic depth } & \multicolumn{2}{|c|}{ Recovery } \\
\hline & & & & Poor & Redosing & Lidocaine & Score > 8 & Poor & Prolonged \\
\hline 10 & 3 & 0.15 & 2 & 0 & 1 & 1 & 0 & 0 & 1 \\
\hline 15 & 3 & 0.15 & 4 & 0 & 1 & 0 & 2 & 1 & 1 \\
\hline 20 & 3 & 0.15 & 4 & 0 & 0 & 2 & 1 & 3 & 0 \\
\hline 15 & 3 & 0.2 & 4 & 0 & 0 & 1 & 2 & 0 & 0 \\
\hline
\end{tabular}

\subsection{Anaesthesia in the G5-6 piglets}

In G5-6, 37 piglets in the age of $36.3 \pm 2.6$ days were investigated. Breeds included were Landrace $(n=14), F 1$ (Landrace $x$ Large White, $n=12)$ and F1 x Duroc $(n=11)$.rBW was $8.1 \pm 2.6 \mathrm{~kg}$ and was misestimated by $1 \pm 14 \%$.

Five protocols were investigated (Table 4). 
Induction of anaesthesia was smooth in all piglets except of 2 that showed ataxia, paddling and jumping.

It took $6.9 \pm 2.0$ min until piglets were scored ready for castration, except 4 piglets that needed redosing $10 \mathrm{~min}$ post injection. They had received $0.15 \mathrm{mg} / \mathrm{kg}$ romifidine (vs. 0.20 $\mathrm{mg} / \mathrm{kg}$ ). One of them failed to become anaesthetized even after re-dosing and the additional application of $3 \mathrm{mg} / \mathrm{kg}$ ketamine IV. In 13 animals, anaesthesia was not deep enough for castration; 2 of them required lidocaine and 11 had a score $>8(16.2 \pm 5.2)$ and VAS of $6.8 \pm$ 1.1 (vs. score of $3.7 \pm 2.8$ and VAS of $1.4 \pm 1.4$ in animals with sufficient anaesthesia).

Surprisingly, almost all remaining piglets were excellently anaesthetized and only few ones showed a moderate plane of anaesthesia.

Recovery was turbulent in 1 piglet with impulsive forward movement and was prolonged in 6 piglets. Mild, intermittent paddling was observed in 6 piglets.

All dose-rate modifications were undertaken in order to deepen anaesthesia. The end of the decision tree was reached without finding a satisfying protocol in this age group.

Table 4: Ketamine (ket), azaperone (aza) and romfidine (rom) dosages tested and reasons for rejection of the tested anaesthesia protocols in 5-6 weeks old piglets.

\begin{tabular}{|l|l|l|c|c|c|c|c|c|c|}
\hline \multicolumn{3}{|c|}{ Dosage (mg/kg) } & Piglets & \multicolumn{5}{|c|}{ Reasons for rejection of the tested protocol } \\
\hline Ket & Aza & Rom & Total & Induction & \multicolumn{3}{|c|}{ Anaesthetic depth } & \multicolumn{2}{|c|}{ Recovery } \\
\hline & & & & Poor & Redosing & Lidocaine & Score > 8 & Poor & Prolonged \\
\hline 10 & 3 & 0.15 & 4 & 0 & 2 & 0 & 2 & 0 & 0 \\
\hline 15 & 3 & 0.15 & 4 & 2 & 0 & 1 & 1 & 1 & 1 \\
\hline 15 & 4 & 0.15 & 5 & 0 & 2 & 1 & 0 & 0 & 0 \\
\hline 15 & 4 & 0.2 & 9 & 0 & 0 & 0 & 4 & 0 & 1 \\
\hline 20 & 4 & 0.2 & 15 & 0 & 0 & 0 & 4 & 0 & 4 \\
\hline
\end{tabular}




\section{Discussion}

In an attempt to improve anaesthesia quality of the currently used unsatisfactory standard anaesthesia combination of ketamine and azaperone for piglets (Enz et al., 2013b), the present study tested the suitability of a potent sedative analgesic $\alpha 2$-agonist, romifidine, as an additive drug. Several drug dosages previously published were tested. None of the anaesthetic protocols fulfilled the requirements of a calm induction of anaesthesia, sufficient anaesthetic depth for castration and calm recovery shorter than $2 \mathrm{~h}$ in 3-4 and 5-6 weeks old piglets. In the present study, a so-called decision tree was used, that was designed based on known effects and untoward side effects of the drugs used and dose rates published by other authors. Maximal dose rates of each drug were predetermined representing highest dose rates considered safe in other publications about anaesthesia in pigs. The highest dose of romifidine tested was $0.2 \mathrm{mg} / \mathrm{kg}$ as it has been reported, that with higher dose rates pigs show excitations instead of desired sedation (Baab, 1986). It was presumed that a lack in depth of anaesthesia could be targeted with an increase of either ketamine or romifidine or both. Excitations during recovery were assumed to be caused by ketamine and in order to cease further excitations, ketamine dosage was reduced or sedation improved by increasing azaperone or romifidine dose. In case of perfect anaesthesia with prolonged recoveries, the dose of azaperone would have been adjusted.

Achievement of adequate anaesthetic plane for castration imposed the main difficulty in both age groups. In G3-4 the predetermined maximum dosage of ketamine (20 mg/kg) failed to provide sufficient anaesthesia in 3 of 4 consecutively castrated animals and was associated in as many pigs with attacks of tonic-clonic excitements during recovery. Since ketamine was thought to be cause of these excitements, following ketamine doses were reduced. In an attempt to provide nevertheless enough analgesia for castration, the dose of romifidine was increased to $0.2 \mathrm{mg} / \mathrm{kg}$, the predetermined maximal dose. However, in 3 out of 4 castrated pigs anaesthetic depth remained unsatisfactory.

In G5-6 only the predetermined maximum dosages of anaesthetics ( $20 \mathrm{mg} / \mathrm{kg}$ ketamine, 4 $\mathrm{mg} / \mathrm{kg}$ azaperone, $0.2 \mathrm{mg} / \mathrm{kg}$ romifidine,) resulted in a satisfying anaesthetic quality for castration in 11 of 15 animals and calm recoveries, that were prolonged in 4 pigs. This is much better than previously reported in a study with 9 weeks old pigs from the same research group, where 23 of 28 pigs anaesthetized with standard dose rates of ketamine, azaperone and butorphanol required one or several additional doses of ketamine-azaperone in order to enable castration (Bettschart-Wolfensberger et al., 2013). In contrast to this, the same standard anaesthetic protocol for piglet castration produced good to very good anaesthesia in all 140 
piglets, that were tested (Nussbaumer et al., 2011), maybe as a consequence of differences in scoring systems or geetics of the piglets. A trial with 1-2 weeks old piglets concluded, that breed has a relevant influence on quality of anaesthesia with overall better results in Landrace pigs than in Large White pigs (Berchtold, 2015). Animal number in the present study was too small in order to further elucidate this problem. However, breed-affiliation could explain inconsistent results of different studies regarding quality of anaesthesia.

In the present study, we expected superior anaesthesia quality in older pigs, as other injection anaesthesia studies have previously shown this. A study investigating the pharmacokinetics and metabolism of ketamine in swine reported an age-dependent difference in drug-potency: Whereas in adult sows (188-200 kg BW) the application of $15 \mathrm{mg} / \mathrm{kg}$ ketamine IM produced profound analgesia, this effect was not obtained in young pigs (21-32 kg BW) (Löscher, 1990). In accordance to these investigations, an observational study reported a lower occurrence of unsatisfactory anaesthesia during castration of heavy compared to light piglets (body weight not mentioned) (Enz et al., 2013b). These observations are not related to pharmacokinetic differences between young and adult swine (Löscher, 1990). One author attributed the higher drug-requirements to the higher metabolic rate of young animals (Lahrmann, 2006) and another came to the conclusion that it was a consequence of the different extracellular water content and its influence on drug distribution (Ganter et al., 1990). As ketamine is highly water soluble, an increase of ketamine dose should lead to adequate depth of anaesthesia in younger pigs. We avoided to give dose rates higher than 20 $\mathrm{mg} / \mathrm{kg}$ ketamine, as with this dose rate excitations during recovery were often pronounced in piglets (Thurmon et al., 1972) and interpreted as a sign of relative ketamine overdose or some sort of ketamine hangover. Also a retrospective evaluation of 479 pigs anaesthetized for surgery reported the impossibility to achieve surgical tolerance in weaned piglets even after redosing $20 \mathrm{mg} / \mathrm{kg}$ up to a total dose of $40 \mathrm{mg} / \mathrm{kg}$ ketamine (Lahrmann, 2006). One study hypothesized, that individual response to injectable anaesthetics is the reason for missing surgical depth of anaesthesia in some piglets (Heinonen et al., 2009). Additional causes for poor response to injected drugs could be underestimation of body weight and incorrect injection of the anaesthetic (Hodgkinson, 2007). In our study, the first explanation can be ruled out, as insufficient anaesthesia was not consistently associated with weight underestimation (4 piglets were underestimated, 4 overestimated). Lahrmann (2006) explained missing surgical tolerance even after high doses of anaesthetics by drug deposition into subcutaneous fat. Injection into layers of fat in the muscle becomes more likely with increasing age and fattening. As fat tissue has a poor blood supply (Hodgkinson, 2007), onset 
of action is delayed leading to fail of induction of anaesthesia with prolonged duration of action causing poor recoveries. However, the prolonged recovery noted in 4 out of 15 G5-6 animals that were adequately anaesthetized is not as harmful in that age group as in younger piglets that miss suckling periods. Unacceptable on the other hand is the strong intermittent paddling that appeared during recovery in G3-4. This side effect was caused by racemic ketamine (Ganter et al., 1990), but did not occur when S-Ketamine was used instead (Bettschart-Wolfensberger et al., 2013).

In the present study butorphanol was not included, which probably would have improved depth of anaesthesia. Reason for its omission was the observation of severe side effects in a previous in-house study (Cap et al., 2017).

In the present study, none of the investigated protocols for intramuscular anaesthesia with ketamine, romifidine and azaperone for castration of 3-4 and 5-6 weeks old piglets met the criteria that included excitement-free induction of anaesthesia, sufficient anaesthetic depth for castration and calm recovery shorter than $2 \mathrm{~h}$. Produced anaesthesia was better in 5-6 weeks old piglets, but still not acceptable for broad application. Anyhow, it is not likely that castration in that weight category will become routine, as with increasing age risk of complications is higher, surgery is more difficult and drug costs are severalfold higher (Lackner, 2003). 


\section{References}

Ammer H., Potschka H.: Pharmakologie des zentralen Nervensystems (ZNS). In: Lehrbuch der Pharmakologie und Toxikologie für die Veterinärmedizin. Eds. Frey H., Löscher W., Enke Verlag, Stuttgart, 2010, 133.

Baab U.: Untersuchungen uiber die Eignung des Imidazolidinabkömmlinges STH 2130- Cl, einem Versuchspräparat der Fa. Boehringer Ingelheim, als Neuroleptikum beim Schwein. Dissertation, Justus-Liebig-Universität Giessen, 1986.

Berchtold S.: Optimierung der Injektionsanästhesie für die Ferkelkastration. Dissertation, Universität Zürich, 2015.

Bettschart-Wolfensberger R., Stauffer S., Hässig M., Flaherty D., Ringer S. K.: Racemic ketamine in comparison to S-ketamine in combination with azaperone and butorphanol for castration of pigs. Schweiz. Arch. Tierheilkd. 2013, 12: 669-675.

Cap V. H., Mossa Abass M., Hug P. J., Kümmerlen D., Hug C., Bettschart-Wolfensberger R.: Butorphanol induces anxiety-like behaviour and distress in piglets. 9th european symposium of porcine health management, 2017.

Enz A., Schüpbach-Regula G., Bettschart R., Fuschini E., Bürgi E., Sidler X.: Experiences with pain control during piglet castration in Switzerland Part 1: Inhalation anesthesia. Schweiz. Arch. Tierheilkd. 2013a, 12: 651-659.

Enz A., Schüpbach-Regula G., Bettschart R., Fuschini E., Bürgi E., Sidler X.: Experiences with pain control during piglet castration in Switzerland Part 2: Injection anesthesia. Schweiz. Arch. Tierheilkd. 2013b, 12: 661-668.

Ganter M., Ruppert K., Kanngiesser M.: The development of a residue-poor anesthesia in swine. Berl. Munch. Tierarztl. Wochenschr. 1990, 10: 341-348.

Heinonen M. L., Raekallio M. R., Oliviero C., Ahokas S., Peltoniemi O. A.: Comparison of azaperone-detomidine-butorphanol-ketamine and azaperone-tiletamine-zolazepam for anaesthesia in piglets. Vet. Anaesth. Analg. 2009, 2: 151-157.

Hodgkinson O.: Practical sedation and anaesthesia in pigs. In Practice 2007, 29: 34-39.

Huber-Eicher B., Spring P.: Attitudes of Swiss consumers towards meat from entire or immunocastrated boars: a representative survey. Res. Vet. Sci. 2008, 3: 625-627.

Jiang J., Jiang H.: Effect of the inhaled anesthetics isoflurane, sevoflurane and desflurane on the neuropathogenesis of Alzheimer's disease (review). Mol. Med. Rep. 2015, 1: 3-12.

Kanngiesser M.: Versuche zur Etablierung enier intramuskulären Injektionsnarkose beim Schwein. Dissertation, Tierärztliche Hochschule Hannover, 1988. 
Lackner A.: Untersuchungen zur Schmerzhaftigkeit und der Wundheilung bei der Kastration männlicher Ferkel zu unterschiedlichen Kastrationszeitpunkten. Dissertation, Tierärztiche Fakultät der Ludwig-Maximilians-Universität München, 2003.

Lahrmann K. H.: Klinisch-experimentelle Untersuchungen zur Ketamin/AzaperonAllgemeinanästhesie bei Schweinen. Prakt. Tierarzt 2006, 9: 713-725.

Lin H.: Injectable anesthetics and field anesthesia. In: Farm Animal Anesthesia: Cattle, Small Ruminants, Camelids, and Pigs. Eds. Lin H., Walz, P., Wiley Blackwell, New Jersey, 2014, 60-94.

Löscher W., Ganter, M., Fassbender, C. P.: Correlation between drug and metabolite concentrations in plasma and anesthetic action of ketamine in swine. Am. J. Vet. Res. 1990, 391-398.

Nussbaumer I., Indermühle N., Zimmermann W., Leist Y.: Piglet castration using injection anesthesia: experiences with a combination of azaperone, butorphanol and ketamine. Schweiz. Arch. Tierheilkd. 2011, 1: 33-35.

Thurmon J. C., Nelson D. R., Christie G. J.: Ketamine anesthesia in swine. J. Am. Vet. Med. Assoc. 1972, 9: 1325-1330. 


\section{Acknowledgements}

My special thanks go to Prof. Dr. med. vet. PhD Regula-Bettschart-Wolfensberger for her enthusiastic support. Her door was always open for me and I could ask for advice at any time, even during holidays.

I thank Prof. Dr. med. vet. Fredi Janett for his agreement to take over the second examination and performing it instantly.

A huge thank you belongs to Petra Hug. She helped me during the whole experiment and gave her full support in all respects.

Further, I thank the Division of Swine Medicine, namely Thomas Echtermann, Julia Honegger, Sereina von Ah and Dr. Dolf Kümmerlen, for their time and performance of the castration.

Thanks also go to Iwan Nussbaumer supporting this project and sharing his experience with injection anaesthesia in piglets.

I also thank Samuel Ritter for agreeing to perform the trial on his farm and for his help with the piglets.

My gratitude belongs to Lukas Sprenger, who equipped me with his cameras and gave technical assistance.

Thank you, Elisabeth Ranninger, for the careful review of my thesis.

I am deeply grateful for having the best family and friends in the world and my special thanks belong to them. 


\section{Curriculum vitae}

Vorname Name

Geburtsdatum

Geburtsort

Nationalität

Heimatort

$1997-2003$

$2003-2009$

2009

$2009-2010$

$2010-2016$

2016

$03 / 2016-01 / 2017$

$03 / 2016-01 / 2017$
Veronika Cap

03.05 .1990

Bern BE

Schweizerin

Luzern LU

Primarschule Eselriet, Effretikon, Schweiz

Kantonsschule Oerlikon, Zürich, Schweiz

Eidgenössische Maturität, Altsprachliches Profil

Studium Biologie, Universität Zürich, Schweiz

Studium Veterinärmedizin, Universität Zürich, Schweiz

Staatsexamen, Universität Zürich, Schweiz

Anfertigung der Dissertation unter Leitung von Prof. Dr. med. vet. PhD Regula Bettschart-Wolfensberger an der Abteilung für Anästhesiologie, Departement für Pferde, Vetsuisse Fakultät, Universität Zürich

Direktor: Prof. Dr. med. vet. Anton Fürst

Assistenztierärztin, Abteilung für Anästhesiologie, Departement für Pferde, Vetsuisse-Fakultät, Universität Zürich, Schweiz 